Case report

\title{
Isolated long thoracic nerve paralysis - a rare complication of anterior spinal surgery: a case report Ebrahim Ameri ${ }^{1}$, Hamid Behtash ${ }^{1}$ and Farzad Omidi-Kashani ${ }^{2}{ }^{*}$
}

\author{
Addresses: ${ }^{1}$ Department of Spine Surgery, Shafa Yahyaeean Hospital, Tehran, Iran and ${ }^{2}$ Department of Orthopedic Surgery, Qaem Hospital, \\ Mashhad, Iran \\ Email: EA - ebrahim.ameri@yahoo.com; HB - hbehtash@yahoo.com; FOK* - omidif@mums.ac.ir \\ * Corresponding author
}

Received: 4 October 2008 Accepted: 29 January 2009 Published: 23 June 2009

Journal of Medical Case Reports 2009, 3:7366 doi: 10.4076/1752-1947-3-7366

This article is available from: http://jmedicalcasereports.com/jmedicalcasereports/article/view/7366

(C) 2009 Ameri et al; licensee Cases Network Ltd.

This is an Open Access article distributed under the terms of the Creative Commons Attribution License (http://creativecommons.org/licenses/by/3.0), which permits unrestricted use, distribution, and reproduction in any medium, provided the original work is properly cited.

\begin{abstract}
Introduction: Isolated long thoracic nerve injury causes paralysis of the serratus anterior muscle. Patients with serratus anterior palsy may present with periscapular pain, weakness, limitation of shoulder elevation and scapular winging.

Case presentation: We present the case of a 23-year-old woman who sustained isolated long thoracic nerve palsy during anterior spinal surgery which caused external compressive force on the nerve.

Conclusion: During positioning of patients into the lateral decubitus position, the course of the long thoracic nerve must be attended to carefully and the nerve should be protected from any external pressure.
\end{abstract}

\section{Introduction}

Isolated long thoracic nerve paralysis causes weakness of the serratus anterior muscle and winging of the scapula $[1,2]$. The normal function of the serratus anterior muscle is to maintain the scapula in apposition to the thorax when the arm is elevated forward at the shoulder [1]. Paralysis of the serratus anterior muscle causes the scapula to rotate posteriorly on its vertical axis, producing the characteristic appearance of winging of the scapula $[1,2]$. So far, several traumatic and non-traumatic causes of damage to the long thoracic nerve have been reported $[3,4]$. We present a patient with long thoracic nerve palsy caused by the direct compression of the nerve during anterior spinal surgery. To the best of our knowledge this is the first case report of this complication in the literature.

\section{Case presentation}

Our patient was a 23-year-old woman with a history of a car accident and an L1 flexion-distraction injury, which had been treated in another center by posterior spinal fusion and instrumentation with Cotrel-Dubousset (Figure 1). Nine months later she was referred to our department because of the failure of the instrumentation and resultant thoracolumbar kyphosis (Figure 2). She was neurologically intact. We first removed the failed instrument via a posterior approach; a week later anterior spinal 


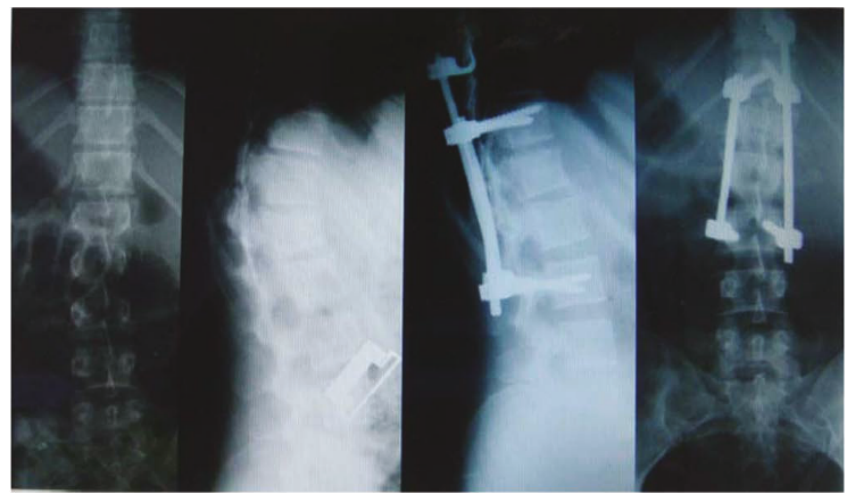

Figure I. Initial radiographs. The initial trauma caused LI-L2 flexion-distraction injury. The patient was first treated by posterior spinal fusion and instrumentation from TII to L3.

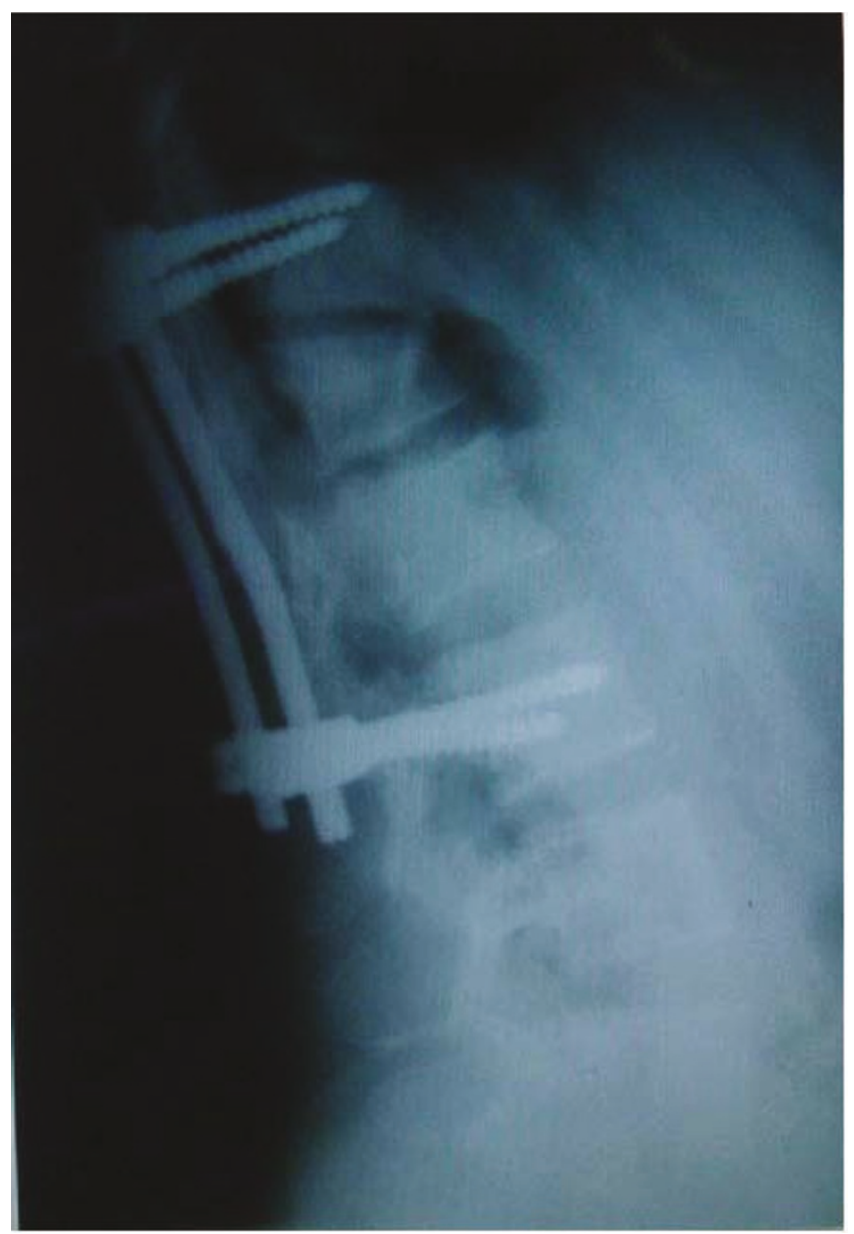

Figure 2. Nine months after the primary surgery. Nine months after the primary operation the patient presented with implant failure and thoracolumbar kyphosis. release and fusion was performed. In this procedure the patient was positioned in the right lateral decubitus position (right side down) with the table flexed and a rolled towel under her axilla in order to remove the pressure from the brachial plexus and axillary vessels. Her spine was exposed by the left thoracoabdominal approach and the tenth rib resected. In the third stage, one week later, she underwent posterior spinal fusion and instrumentation. The radiographic result was satisfactory (Figure 3).

She was discharged with a total contact body brace and, after 2 weeks, on the first postoperative visit, she complained of weakness of the right upper limb during overhead activities, mild fatigue and pain in the right periscapular region. On physical examination, the right upper limb was intact for both sensory and motor innervation, but the right scapula was winged and she was not able to flex her arm forward over $60^{\circ}$.

An electrodiagnostic study carried out two months later revealed an isolated long thoracic nerve lesion. The patient was treated conservatively using physical therapy and observation. As a result, the weakness of her serratus anterior muscle has lessened gradually, but on her last visit five years after the surgery some weakness was still detectable and, although she could manage her daily activities without fatigue, mild winging was still present during overhead activities (Figure 4). Finally, in the last electrodiagnostic study that was carried out 5 years after the surgery, partial and incomplete regeneration of the long thoracic nerve was reported. Although we had offered her neurolysis or nerve decompression [5-7] for her

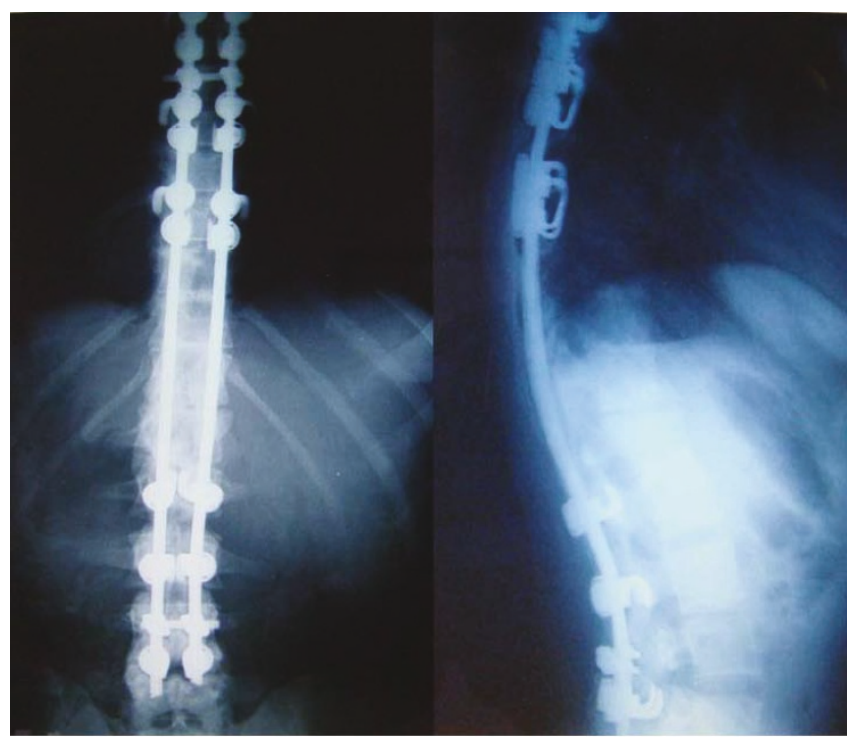

Figure 3. Final radiographs. Posteroanterior and lateral views after the three stages of surgery. 


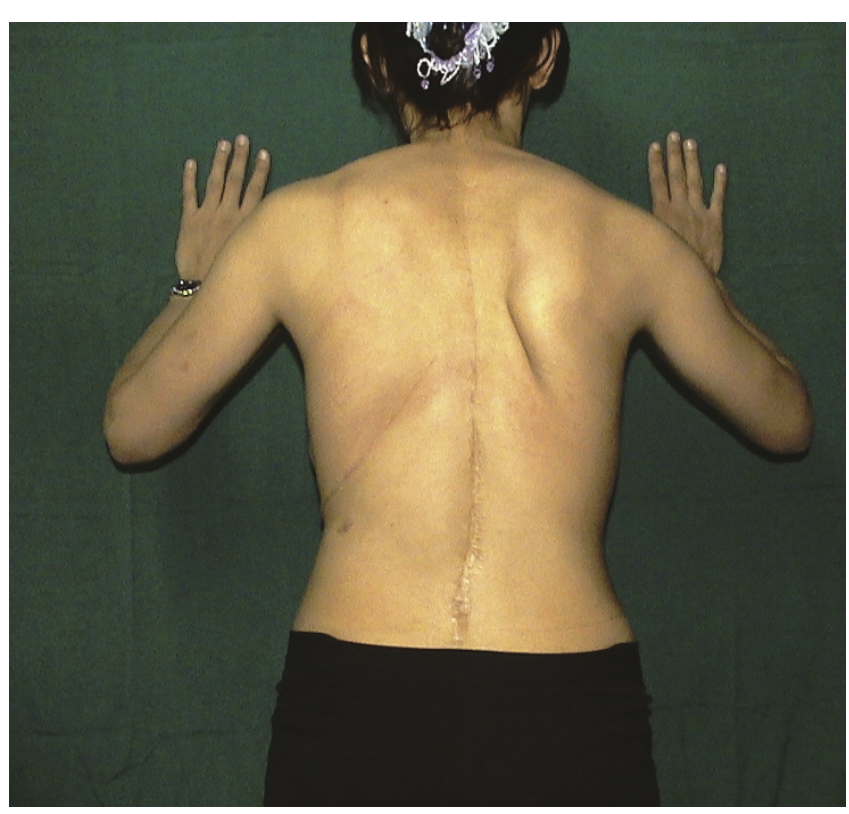

Figure 4. Latest photograph. Winging of the right scapula in pushing posture in the last follow-up visit 5 years after the surgery.

limited dysfunction she did not want to be operated on again.

According to the details of the electrodiagnostic studies we carried out, the site of injury was around the axillary folds. The site exactly correlated with the location in which we had inserted the axillary roll.

\section{Discussion}

The serratus anterior is a broad muscle that has its origin in the first through to the ninth ribs. The muscle extends posteriorly and inserts on the medial border of the scapula. The long thoracic nerve, which is derived from the ventral rami of the fifth, sixth and seventh cervical nerve roots, travels over the first rib and descends on the lateral aspect of the chest wall where it divides and innervates the serratus anterior muscle $[1,2]$.

The function of the serratus anterior muscle is to stabilize the scapula against the chest wall while elevating the arm. In initial abduction, the serratus anterior fixes the scapula so that the supraspinatus and deltoid muscles can act effectively on the humerus raising the extremity to the right angle. The serratus anterior and trapezius muscles simultaneously rotate the scapula so that the arm can be raised to the vertical position $[1,2,4]$. When this muscle is paralyzed, the scapula's medial border, and especially its lower angle, stands out prominently. The patient cannot raise the arm fully or push, and attempts to do so are followed by further projection or "winging of scapula" $[1,2,4]$. Due to its long and superficial course, the long thoracic nerve is vulnerable to damage at various levels. Several causes of its damage have been reported, including closed trauma, compression, stretching, traction, direct extrinsic force, penetrating injury, improper surgical technique, electrocution, chiropractic manipulation, various sport-related injuries including tennis, hockey, bowling, soccer, gymnastics, and weight lifting, deep massage, repetitive overhead movement, bracing for back deformity, iatrogenesis, viral infection and neuritis such as Parsonage-Turner syndrome [8-20]. Scapular winging can also result from repetitive or sudden external biomechanical forces that may either exert compression or place extraordinary traction in the course of the long thoracic nerve [16-18].

In our patient, during the anterior spinal surgery she was in the right lateral decubitus position with a rolled towel under her axilla. The operation took four hours and it appears that external compression on the nerve during surgery was the most probable cause of the nerve palsy.

Since this event we have changed patient positioning during lateral decubitus surgeries. Before this, we placed the chest or axillary roll under the dependent chest wall just beneath the axilla to take pressure off the dependent shoulder and to prevent compression of the neurovascular bundle by the humeral head. Now, we place the roll about $10 \mathrm{~cm}$ distal to the axillary folds, roughly over the seventh to ninth ribs. This new position not only does the same as before, but also protects the main trunk of the long thoracic nerve from injury (Figure 5).

Iatrogenic injuries to the nerve have been reported during needle thoracocentesis, breast reconstruction, cardiac surgery, anesthetic block of the brachial plexus and chest tube placement [12-15]. In all of these iatrogenic injuries the nerve was directly traumatized, but in our patient the injury was secondary to an external compressing force.

\section{Conclusion}

During positioning of patients into the lateral decubitus position the course of the long thoracic nerve must be attended to carefully and the nerve should be protected from any external pressure.

\section{Consent}

Written informed consent was obtained from the patient for publication of this case report and any accompanying images. A copy of the written consent is available for review by the Editor-in-Chief of this journal.

\section{Competing interests}

The authors declare that they have no competing interests. 


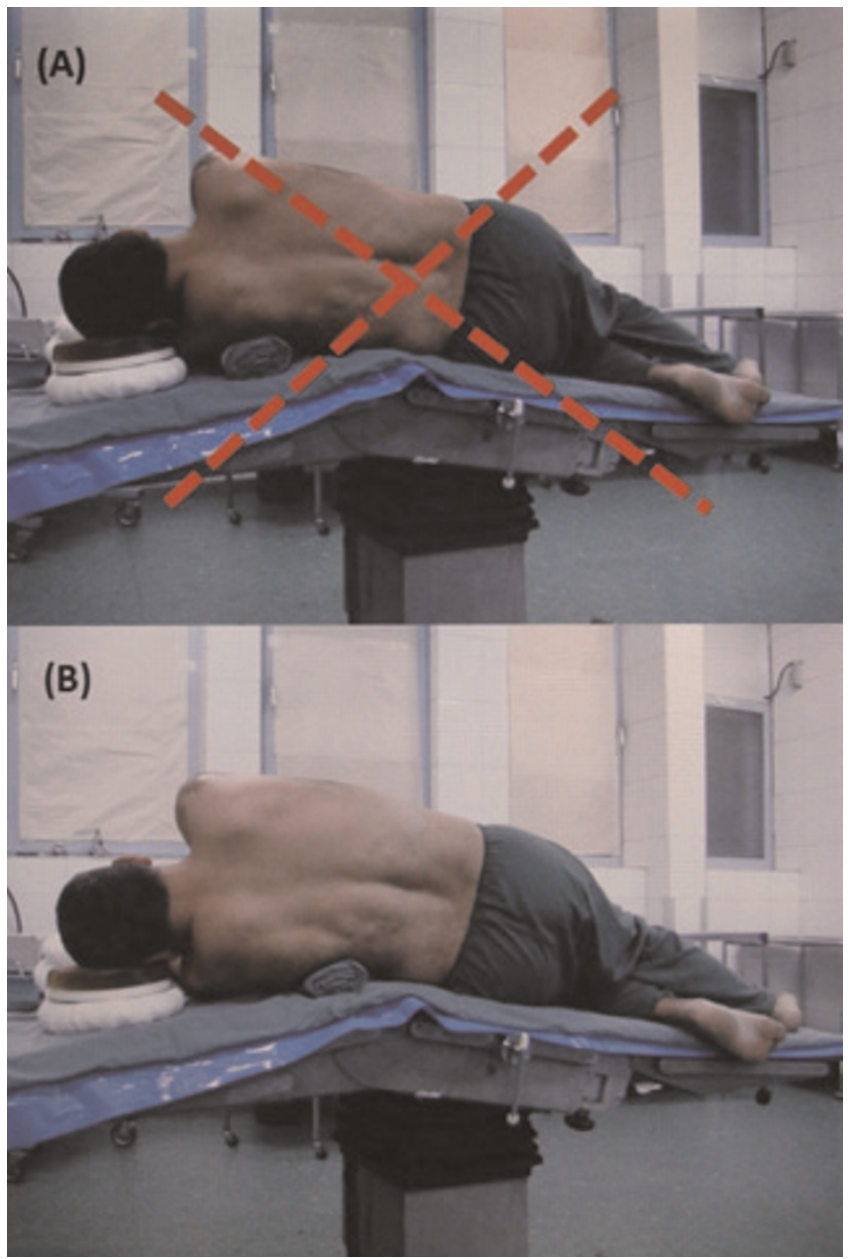

Figure 5. Incorrect and correct positioning. The image shows the previous (A) and current method (B) of our patient positioning during lateral decubitus surgery.

\section{Authors' contributions}

EA participated in the sequence alignment and drafted the manuscript. HB participated in the design of the study. FOK conceived of the study and participated in its design and coordination. All authors read and approved the final manuscript.

\section{Acknowledgements}

We would like to express our gratitude to Katayoun $\mathrm{Z}$ Toossi for her help in reviewing, editing and correcting this paper.

\section{References}

I. Hollinshead WH: Anatomy for Surgeons. 3rd edition. Philadelphia: Harper and Row; 1998.

2. Bertelli JA, Ghizoni MF: Long thoracic nerve: anatomy and functional assessment. J Bone Joint Surg Am 2005, 87:993-998.

3. Gozna ER, Harris WR: Traumatic winging of the scapula. J Bone Joint Surg Am 1979, 61:1230-1233.
4. Wiater JM, Flatow EL: Long thoracic nerve injury. Clin Orthop Relat Res 1999, 368:17-27.

5. Nath RK, Lyons AB, Bietz G: Microneurolysis and decompression of long thoracic nerve injury are effective in reversing scapular winging: long-term results in $\mathbf{5 0}$ cases. BMC Musculoskelet Disord 2007, 8:25.

6. Nath RK, Melcher SE: Rapid recovery of serratus anterior muscle function after microneurolysis of long thoracic nerve injury. J Brachial Plex Peripher Nerve Inj 2007, 2:4.

7. Disa JJ, Wang B, Dellon AL: Correction of scapular winging by supraclavicular neurolysis of the long thoracic nerve. J Reconstr Microsurg 2001, 17:79-84.

8. Patel DR, Nelson TL: Winging of the scapula in a young athlete. Adolesc Med 1996, 7:433-438.

9. Packer GJ, McLatchie GR, Bowden W: Scapula winging in a sports injury clinic. Br J Sports Med 1993, 27:90-91.

10. Ebata A, Kokubun N, Miyamoto T, Hirata K: The bilateral long thoracic nerve palsy presenting with "scapula alata", as a result of weight training. A case report. Rinsho Shinkeigaku 2005, 45:308-3II.

II. Oakes MJ, Sherwood DL: An isolated long thoracic nerve injury in a Navy Airman. Mil Med 2004, 169:713-7I5.

12. Bizzarri F, Davoli G, Bouklas D, Oncchio L, Frati G, Neri E: latrogenic injury to the long thoracic nerve: an underestimated cause of morbidity after cardiac surgery. Tex Heart Inst ] 200I, 28:315-317.

13. Durand LS: Winging of the scapula in patients for breast reconstruction. Plast Reconstr Surg 1984, 74:153-154.

14. Faruqi S, Raychaudhuri C, Thirumaran M, Blaxill P: Winging of the scapula: An unusual complication of needle thoracocentesis. Eur J Intern Med 2008, 19:38I-382.

15. Hassan WU, Keaney NP: Winging of the scapula: an unusual complication of chest tube placement. J Accid Emerg Med 1995, I 2:156-I57.

16. Debeer P, Van Den Eede E, Moens P: Scapular winging: an unusual complication of bracing in idiopathic scoliosis. Clin Orthop Relat Res 2007, 46I:258-26I.

17. Elders LA, Van der Meche FG, Burdorf A: Serratus anterior paralysis as an occupational injury in scaffolders: two case reports. Am J Ind Med 200I, 40:710-7I3.

18. Gupta $V$, Posner B: Trauma to the long thoracic nerve and associated scapula winging in a low-velocity rear-end automobile collision: case report. J Trauma 2004, 57:402-403.

19. Still JM, Law EJ, Duncan JW, Hughes HF: Long thoracic nerve injury due to an electric burn. J Burn Care Rehabil 1996, 17:562564.

20. Zander D, Perlick L, Diedrich O: Scapula alata as a complication of infection with human parvovirus B 19 (erythema infectiosum). Z Orthop Ihre Grenzgeb 200I, 139:174-176. 